\title{
Five Years Data of Clinical and Histopathological Characteristics of Skin Adnexal Tumors in Dr. Hasan Sadikin General Hospital Bandung
}

\author{
Jessica Oktavianus Trisaputra, ${ }^{1}$ Hermin Aminah Usman, ${ }^{2}$ Reti Hindritiani ${ }^{3}$ \\ ${ }^{1}$ Faculty of Medicine Universitas Padjadjaran, ${ }^{2}$ Department of Anatomic Pathology Faculty of \\ Medicine Universitas Padjadjaran/Dr. Hasan Sadikin General Hospital Bandung, Indonesia, \\ ${ }^{3}$ Department of Dermato-Venerology Faculty of Medicine Universitas Padjadjaran/Dr. Hasan \\ Sadikin General Hospital Bandung, Indonesia
}

\begin{abstract}
Background: Skin adnexal tumors arise from skin adnexal differentiation. Very limited number of study has been performed on their clinical and histopathological characteristics in Dr. Hasan Sadikin General Hospital. The objectives of this study was to identify the clinical and histopathological characteristic of skin adnexal tumors during the period of 2009 to 2013.

Methods: AA descriptive study performed on 79 medical records of patients with skin adnexal tumors at the Department of Anatomic Pathology in Dr. Hasan Sadikin General Hospital Bandung from 2009 to 2013. Data were collected during the period of September to October 2014. The inclusion criteria were medical records containing information on skin adnexal tumors confirmed by histopathological examination results, patient characteristics (age and gender), and the tumor characteristics (size, location, malignancy, type, and histopathological origin). Collected data were processed using computer and presented in tables.

Results: This study showed that tumors occured during productive age with male to female ratio was 1.2:1. Most skin adnexal tumors were $\leq 5 \mathrm{~cm}$ in size and were distributed in the head-neck region. Most of the tumors were benign and arised from hair follicle differentiation with pilomatricoma type while the malignant tumors commonly arised from sebaceous gland differentiation with sebaceous carcinoma type. Conclusions: Mostskin adnexal tumors occur in productive age with no gender prediclation. They are small in size and are distributed in the cephalic region. Most are benign tumors arising from hair follicle differentiation with some malignant tumors arising from sebaceous gland differentiation. [AM].2016;3(4):514-9]
\end{abstract}

Keywords: Clinical characteristic, histopathologic characteristic, skin adnexal tumor

\section{Introduction}

Skin adnexal tumors (SAT) arise from skin adnexal differentiations that take place in, among others, sebaceous gland, hair follicle, and eccrine/apocrine sweat glands. ${ }^{1}$ The incidence of skin adnexal tumors is low as seen in Iran (3.3\%), Netherland (1.23\%), and Nigeria $(0.9 \%))^{2-4}$ The mean age of patients is in the third decade of life for benign tumors and above 50 years old for malignant tumors. ${ }^{2}$ The clinical characteristics of benign skin adnexal tumors include nodules or papules, skin-colored, $\leq 5 \mathrm{~cm}$ in size while for the malignant tumors, there are plaques or ulcers, $>5 \mathrm{~cm}$ in size. ${ }^{5}$ The most common location of the skin adnexal tumors is the head-neck area due to the presence of many skin adnexals in that area. ${ }^{1}$ The etiology are mostly genetics, such as seen in trichoepithelioma (PTCH1 gene mutation) or cylindroma (CYLD mutation) with some cases are triggered by ultraviolet radiation or immunesuppresed condition. ${ }^{6,7}$

Skin adnexal tumors can be classified into benign and malignant tumors. ${ }^{5}$ The incidence of benign skin adnexal tumors is higher than that of the malignant tumors. ${ }^{2,4,8-10}$ Skin adnexal tumors are classified based on World Health Organization (WHO) Histological Classification of Appendageal Tumours which includes tumors from sebaceous gland differentiation, hair follicle differentiation, and eccrine/apocrine sweat gland differentiation. ${ }^{5}$

Very limited studies have been performed on the clinical and histopathological characteristics of skin adnexal tumors in Dr.

Correspondence: Jessica Oktavianus Trisaputra, Faculty of Medicine, Universitas Padjadjaran, Jalan Raya BandungSumedang Km.21, Jatinangor, Sumedang, Indonesia, Phone: +6281298598525 Email: jessicaoktavianus@gmail.com 
Jessica Oktavianus Trisaputra, Hermin Aminah Usman, Reti Hindritiani: Five Years Data of Clinical and 515 Histopathological Characteristics of Skin Adnexal Tumors in Dr. Hasan Sadikin General Hospital Bandung

Hasan Sadikin General Hospital yet. Hence, the objectives of this study was to identify the clinical and histopathological characteristics of skin adnexal tumors in Dr. Hasan Sadikin General Hospital during the period of 2009 to 2013.

\section{Methods}

This descriptive study reviewed medical records of patients with skin adnexal tumors at the Department of Anatomic Pathology of Dr. Hasan Sadikin General Hospital Bandung which dated from 2009 to 2013. Samples were collected using total sampling method from September-October 2014. Data were collected based on the inclusion criteria: medical records containing information on skin adnexal tumors confirmed by histopathological examination, patient characteristics (age and gender), and tumor characteristics (size, location, malignancy, type and histopathological origin of the lesions).

The histopathological origin was determined based on the WHO Histological Classification of Appendageal Tumours, namely sebaceous gland differentiation origin, hair follicle differentiation origin, and eccrine/ apocrine sweat gland differentiation origin.

The collected data were processed by using a computer program and were presented in tables. This study had been approved by the ethical comittee and the president director of Dr. Hasan Sadikin General Hospital Bandung.

\section{Results}

There were 105 medical records collected from January 2009 to December 2013, but only 79 medical records were eligible based on the inclusion criteria of this study.

This study showed that the incidence of skin adnexal tumors occured in all ages but mostly occured in the productive age. The interesting finding in this study was that this tumor was also discovered in a very young age (Table 1 ).

Most tumors found were $\leq 5 \mathrm{~cm}$ and located in the cephalic (head-neck) area. In terms of malignancy and the origin of the tumor, most of them were benign and originated from hair follicle differentiation. Most of the benign skin adnexal tumors arised from hair follicle differentiation and most of the malignant skin adnexal tumros arised from sebaceous gland differentation. (Table 2).

There were 29 cases of skin adnexal tumors with hair follicle differentiation with pilomatricoma, trichoepithelioma and tricholemmal carcinoma, in descending order, as the most common types (Table 3).

There were 25 cases of skin adnexal tumors with eccrine/apocrine sweat gland differentiation with porocarcinoma, syringocystadenoma papilliferum and eccrine carcinoma, in descending order, as the most common types (Table 4).

There were 25 cases of skin adnexal tumors with sebaceous glands differentiation and the most common type was sebaceous carcinoma (Table 5).

Table 1 Characteristics of Patients with Skin Adnexal Tumors

\begin{tabular}{|c|c|c|}
\hline & teristics & $\underset{n=79}{\substack{\text { Frequency } \\
(\%)}}$ \\
\hline \multirow[t]{10}{*}{ Age } & $0-9$ years & $6(8 \%)$ \\
\hline & $10-19$ years & $12(15 \%)$ \\
\hline & $20-29$ years & $6(8 \%)$ \\
\hline & $30-39$ years & $12(15 \%)$ \\
\hline & $40-49$ years & $13(16 \%)$ \\
\hline & $50-59$ years & $12(15 \%)$ \\
\hline & $60-69$ years & $9(11 \%)$ \\
\hline & 70-79 years & $6(8 \%)$ \\
\hline & 80-89 years & $2(3 \%)$ \\
\hline & 90-99 years & $1(1 \%)$ \\
\hline \multirow[t]{2}{*}{ Gender } & Male & $40(51 \%)$ \\
\hline & Female & $39(49 \%)$ \\
\hline
\end{tabular}


Table 2 Skin Adnexal Tumor Characteristics

\begin{tabular}{llc}
\hline & Characteristics & $\begin{array}{c}\text { Frequency (\%) } \\
\mathbf{n}=\mathbf{7 9}\end{array}$ \\
\hline Gender & Male & $40(50.63 \%)$ \\
Size & Female & $39(49.37 \%)$ \\
& $\leq 5 \mathrm{~cm}$ & $63(79.75 \%)$ \\
Location & $>5 \mathrm{~cm}$ & $16(20.25 \%)$ \\
& Head-Neck (Cephalic) & $59(74.68 \%)$ \\
Malignancy & Non Head-Neck (Non-Cephalic) & $20(25.32 \%)$ \\
\multirow{4}{*}{ Histopathological origin } & Benign & $43(54.43 \%)$ \\
& Malignant & $36(45.57 \%)$ \\
& Hair Follicle & $29(36.71 \%)$ \\
Benign Tumor & Eccrine/Apocrine Sweat Gland & $25(31.65 \%)$ \\
& Sebaceous Gland & $25(31.64 \%)$ \\
& Hair Follicle & $23(53.49 \%)$ \\
Malignant Tumor & Eccrine/Apocrine Sweat Gland & $13(30.23 \%)$ \\
& Sebaceous Gland & $7(16.28 \%)$ \\
& Hair Follicle & $6(16.67 \%)$ \\
& Eccrine/Apocrine Sweat Gland & $12(33.33 \%)$ \\
& Sebaceous Gland & $18(50 \%)$ \\
\hline
\end{tabular}

There were 13 cases of Paget's disease of breast which were excluded from the study because all of Paget's disease of breast were found with ductal mammae carcinoma and none was isolated from the ductal mammae carcinoma. The mean age of patients with Paget's disease of breast was 49.4 years old and all were female. Most of this tumors were found with size $\leq 5 \mathrm{~cm}$ and all in non-cephalic area/breast (Table 6).

Table 3 Distribution of Hair Follicle Differentiation of Skin Adnexal Tumors Based on Clinical Characteristics

\begin{tabular}{|c|c|c|c|c|c|c|c|c|}
\hline \multirow{2}{*}{$\begin{array}{l}\text { Hair Follicle Differentiation } \\
\text { of Skin Adnexal Tumors }\end{array}$} & \multirow[b]{2}{*}{ n (\%) } & \multirow{2}{*}{$\begin{array}{c}\text { Mean } \\
\text { Age } \\
\text { (years) }\end{array}$} & \multicolumn{2}{|c|}{ Gender } & \multicolumn{2}{|c|}{ Size } & \multicolumn{2}{|c|}{ Location } \\
\hline & & & M & $\mathbf{F}$ & $\leq 5 \mathrm{~cm}$ & $>5 \mathrm{~cm}$ & Cephalic & $\begin{array}{c}\text { Non- } \\
\text { cephalic }\end{array}$ \\
\hline \multicolumn{9}{|l|}{ Benign } \\
\hline Pilomatricoma & $12(15 \%)$ & 20.5 & 5 & 7 & 11 & 1 & 8 & 4 \\
\hline Tricholemmoma & $1(1 \%)$ & 26 & - & 1 & 1 & - & 1 & - \\
\hline Trichoepithelioma & $9(11 \%)$ & 39.3 & 5 & 4 & 9 & - & 9 & - \\
\hline Trichofolliculoma & $1(1 \%)$ & 10 & - & 1 & 1 & - & 1 & - \\
\hline \multicolumn{9}{|l|}{ Malignant } \\
\hline Trichoblastic carcinoma & $1(1 \%)$ & 55 & - & 1 & 1 & - & 1 & - \\
\hline Tricholemmal carcinoma & $3(3 \%)$ & 42 & 1 & 2 & 1 & 2 & 3 & - \\
\hline Pilomatrix carcinoma & $1(1 \%)$ & 52 & 1 & - & - & 1 & 1 & - \\
\hline Proliferating tricholemmal cyst & $1(1 \%)$ & 80 & 1 & - & 1 & - & 1 & - \\
\hline
\end{tabular}


Jessica Oktavianus Trisaputra, Hermin Aminah Usman, Reti Hindritiani: Five Years Data of Clinical and 517 Histopathological Characteristics of Skin Adnexal Tumors in Dr. Hasan Sadikin General Hospital Bandung

Table 4 Distribution of Eccrine/Apocrine Sweat Gland Differentiation of Skin Adnexal Tumors Based on Clinical Characteristics

\begin{tabular}{|c|c|c|c|c|c|c|c|c|}
\hline \multirow{2}{*}{$\begin{array}{c}\text { Eccrine/Apocrine Sweat } \\
\text { Gland Differentiation of Skin } \\
\text { Adnexal Tumors }\end{array}$} & \multirow[b]{2}{*}{ n(\%) } & \multirow{2}{*}{$\begin{array}{l}\text { Mean } \\
\text { Age } \\
\text { (years) }\end{array}$} & \multicolumn{2}{|c|}{ Gender } & \multicolumn{2}{|c|}{ Size } & \multicolumn{2}{|c|}{ Location } \\
\hline & & & M & $\mathbf{F}$ & $\leq 5 \mathrm{~cm}$ & $>5 \mathrm{~cm}$ & Cephalic & $\begin{array}{c}\text { Non- } \\
\text { cephalic }\end{array}$ \\
\hline \multicolumn{9}{|l|}{ Benign } \\
\hline Syringoma & $3(3 \%)$ & 37.6 & 1 & 2 & 3 & - & 1 & 2 \\
\hline $\begin{array}{l}\text { Syringocystadenoma } \\
\text { papilliferum }\end{array}$ & $4(5 \%)$ & 19.5 & 3 & 1 & 1 & 3 & 4 & - \\
\hline Spiradenoma & $2(2 \%)$ & 29 & 2 & - & 2 & - & - & 2 \\
\hline Poroma & $2(2 \%)$ & 29 & 1 & 1 & 2 & - & - & 2 \\
\hline Adenoma & $1(1 \%)$ & 22 & - & 1 & 1 & - & - & 1 \\
\hline Hidradenoma & $1(1 \%)$ & 12 & - & 1 & 1 & - & 1 & - \\
\hline \multicolumn{9}{|l|}{ Malignant } \\
\hline Spiroadenocarcinoma & $1(1 \%)$ & 47 & 1 & - & 1 & - & - & 1 \\
\hline Hidradenocarcinoma & $1(1 \%)$ & 47 & 1 & - & - & 1 & - & 1 \\
\hline Carcinoma & $4(5 \%)$ & 45.5 & 3 & 1 & 3 & 1 & 4 & - \\
\hline Porocarcinoma & $5(6 \%)$ & 61 & 1 & 4 & 3 & 2 & 2 & 3 \\
\hline Malignant cylindroma & $1(1 \%)$ & 67 & - & 1 & 1 & - & 1 & - \\
\hline
\end{tabular}

\section{Discussion}

There were 79 eligible cases of skin adnexal tumors at the Department of Anatomic Pathology of Dr. Hasan Sadikin General Hospital between January 2009 and December 2013. The finding of this study showed a low frequency of skin adnexal tumors in the 5 -year study. Other authors in South India only found 56 cases of skin adnexal tumors in a 6-year study. ${ }^{11}$ Skin adnexal tumors have low frequency compared to others skin tumors. ${ }^{3}$ Kamyab-Hesari et al. ${ }^{2}$ stated that the frequency of skin adnexal tumors iss higher than reported because many skin adnexal tumors only appeared as asymptomatic benign skin lesions like papules or nodules. ${ }^{2}$

In this study, most skin adnexal tumors were diagnosed in the third to sixth decade of life. This is similar to a study conducted in Aga Khan University, Pakistan ${ }^{12}$ where Kamyab-Hesari et al. ${ }^{2}$ mentioned that patients in second or third decade of life often seek medical attention. ${ }^{2}$

There was no significant sexual predilection between males and females in this study. This finding was similar to what was found in a study by Kamyab-Hesari et al. ${ }^{2}$ and Sharma et al. ${ }^{11}$ The finding of female predominance in the work of Saha ${ }^{4}$, Gayatri et al. ${ }^{8}$ and Nair $^{13}$ is still unclear. They suspected that this condition occured because of bias in biopsy selection due to social or esthethic factor, especially among females. ${ }^{2}$

Most of the sizes of the skin adnexal tumors in this study were $\leq 5 \mathrm{~cm}(78 \%)$ with the benign type being the most common. This is in accordance with Jindal et al. ${ }^{14}$ who stated that most benign skin adnexal tumors are

Table 5 Distribution of Sebaceous Gland Differentiation of Skin Adnexal Tumors Based on Clinical Characteristics

\begin{tabular}{|c|c|c|c|c|c|c|c|c|}
\hline \multirow{2}{*}{$\begin{array}{c}\text { Sebaceous Gland } \\
\text { Differentiation of Skin } \\
\text { Adnexal Tumors }\end{array}$} & \multirow[b]{2}{*}{$n(\%)$} & \multirow{2}{*}{$\begin{array}{l}\text { Mean } \\
\text { Age } \\
\text { (years) }\end{array}$} & \multicolumn{2}{|c|}{ Gender } & \multicolumn{2}{|c|}{ Size } & \multicolumn{2}{|c|}{ Location } \\
\hline & & & M & $\mathbf{F}$ & $\leq 5 \mathrm{~cm}$ & $>5 \mathrm{~cm}$ & Cephalic & $\begin{array}{c}\text { Non- } \\
\text { cephalic }\end{array}$ \\
\hline Sebaceous adenoma & $7(8 \%)$ & 42.8 & 3 & 4 & 7 & - & 7 & - \\
\hline Sebaceous carcinoma & $18(22 \%)$ & 52.7 & 9 & 9 & 12 & 6 & 14 & 4 \\
\hline
\end{tabular}


Table 6 Distribution of Paget's Disease of Breast-based on Clinical Characteristics

\begin{tabular}{|c|c|c|c|c|c|c|c|c|}
\hline & \multirow[b]{2}{*}{ n(\%) } & \multirow{2}{*}{$\begin{array}{c}\text { Mean } \\
\text { Age } \\
\text { (years) }\end{array}$} & \multicolumn{2}{|c|}{ Gender } & \multicolumn{2}{|c|}{ Size } & \multicolumn{2}{|c|}{ Location } \\
\hline & & & $\mathbf{M}$ & $\mathbf{F}$ & $\leq 5 \mathrm{~cm}$ & $>5 \mathrm{~cm}$ & Cephalic & $\begin{array}{c}\text { Non- } \\
\text { cephalic }\end{array}$ \\
\hline Paget's Disease of Breast & $7(8 \%)$ & 42.8 & 3 & 4 & 7 & - & 7 & - \\
\hline
\end{tabular}

usually $\leq 2 \mathrm{~cm}$ in size. Skin adnexal tumors with a size of $\leq 5 \mathrm{~cm}$ are not always considered benign. There are some malignant tumors, namely sebaceous carcinoma or trichilemmal carcinoma which might be $\leq 5 \mathrm{~cm}$ but they are aggressive and can spread to other organs rapidly. ${ }^{5}$

The most common anatomic location for the skin adnexal tumors in this study was in the cephalic (head-neck) area (75\%). The same situation was also reported by other authors in Iran $^{2}$, Nigeria ${ }^{4}$, India ${ }^{10,11}$, and Pakistan. ${ }^{12}$ Skin in cephalic area has more adnexal structure like sweat glands, sebaceous glands, or hair follicles and there will be more progenitor cells for differentiation into skin adnexal tumors. In addition, ultraviolet radiation may contribute to the formation of skin adnexal tumors by damaging the DNA by mutation in signaling pathway due to Reactive Oxygen Species (ROS) or mutation in p53 tumor suppressor gene which enables carcinogenic cells to proliferate without control. ${ }^{1,2,6}$

The ratio between benign and malignant skin adnexal tumors in this study was 1.2:1 with hair follicle differentiation (32\%) becoming the most common histopathological type of the skin adnexal tumors, followed by eccrine/apocrine sweat gland differentiation and sebaceous gland differentiation with the same frequency (32\%). A study in Aga Khan University, Pakistan ${ }^{12}$ also discovered that skin adnexal tumors with hair follicle differentiation are the most common histopathological type; however studies by Samaila ${ }^{4}$, Gayatri et al. ${ }^{8}$, Sharma et al. ${ }^{11}$ have shown different results with eccrine/ apocrine sweat gland differentiation being the most common histopathological type of skin adnexal tumors. It is stated that the diagnosis of skin adnexal tumors is difficult because there are many classification of skin adnexal tumors. Skin adnexal tumors can also arised from more than one differentiation, and there are many and different names are given for skin adnexal tumors.

The greatest number of skin adnexal tumors arise from hair follicle differentiation with pilomatricoma type $(15 \%)$ as the most common followed by trichoepithelioma (11\%), and trichillemal carcinoma (3\%). In this study, pilomatricoma was the most common benign skin adnexal tumors (28\%). Other studies in Iran $^{2}$ and India ${ }^{10,11}$ also show the same result with pilomatricoma as the most common benign skin adnexal tumors. In this study, patients with pilomatricoma have a mean age of 20.5 years old with female predominance, most of them were $\leq 5 \mathrm{~cm}$ in size. Pilomatricoma is the benign skin adnexal tumors with hair follicle matrix differentiation usually found in children and adult in second decade of life. Pilomatricoma is usually found in cephalic area because there are many hairs there. ${ }^{5,15}$

The most common type of skin adnexal tumors in eccrine/apocrine sweat gland differentiation of skin adnexal tumors is porocarcinoma (6\%), followed by syringocystadenoma papilliferum (5\%) and syringoma (3\%).

The most common type of sebaceous gland differentiation of skin adnexal tumors is sebaceous carcinoma (22\%), which is followed by sebaceous adenoma (8\%). In this study, sebaceous carcinoma was the most common malignant skin adnexal tumors rising from sebaceous gland differentiation. The mean age of patient was 52.7 years old with the same gender comparison. Most sebaceous carcinomas had a size of $\leq 5 \mathrm{~cm}$ and were located in the cephalic area. This is in line with Le Boit, et al.5 that sebaceous carcinoma is found in adult aged 62 years old. Athough the size is small and appeared as ulcerative lesions, they are aggressive and can spread to other organs rapidly.

The limitation of this study includes incomplete medical record data leading to inability to describe the course of the illness and clinical characteristics of lesion-like papules or nodules which will be helpful for diagnosis.

It can be concluded that skin adnexal tumors occur in productive age with no gender predilection. Most of the skin adnexal tumors 
Jessica Oktavianus Trisaputra, Hermin Aminah Usman, Reti Hindritiani: Five Years Data of Clinical and 519 Histopathological Characteristics of Skin Adnexal Tumors in Dr. Hasan Sadikin General Hospital Bandung

are $\leq 5 \mathrm{~cm}$ in size and are distributed in cephalic area. The most common skin adnexal tumors are benign and hair follicle differentiation iss the most common histopathological type of skin adnexal tumors with pilomatricoma type. Sebaceous gland differentiation with sebaceous carcinoma type becomes the most common histopathological type of malignant skin adnexal tumors.

It is recommended that data entered into medical records should include complete information the course of illness and clinical characteristics of lesion-like papules in order to enable clinicians to make a proper diagnosis. Skin lesion should be photographed for clearer explanation. The size of the skin adnexal tumors cannot be used as a guide to conclude the behavior of tumors as benign or malignant. Histopathological examination is needed for diagnosis to ensure that the patient receives a proper treatment.

\section{References}

1. Srivastava D, Taylor RS. Appendage tumors and hamartomas of the skin. In: Goldsmith LA, Katz SI, Gilchrest BA, Paller AS, Leffell DJ, Wolff K, editors. Fitzpatrick's dermatology in general medicine. 8th ed. New York: McGraw-Hill Companies, Inc.; 2012. p. 1337-76

2. Kamyab-Hesari K, Balighi K, Afshar N, Aghazadeh N, Rahbar Z, Seraj M, et al. Clinicopathological study of 1016 consecutive adnexal skin tumors. Acta Med Iran. 2014;51(12):879-85.

3. Holterhues C, Vries Ed, Louwman MW, Koljenovic S, Nijsten T. Incidence and trends of cutaneous malignancies in the Netherlands, 1989-2005. J Invest Dermatol. 2010;130(7):1807-12.

4. Samaila M. Adnexal skin tumors in Zaria, Nigeria. Ann of Afr Med. 2008;7(1):6-10.

5. LeBoit PE. Appendageal tumor. In: LeBoit PE, Burg G, Weedon D, Sarasin A, editors. Pathology and genetics skin tumor World Health Organization classification of tumor. Lyon: International Agency for Research on Cancer; 2006. p. 121-63.
6. Blake PW, Bradford PT, Devesa SS, Toro JR. Cutaneous appendageal carcinoma incidence and survival patterns in the United States: a population-based study. Arch Dermatol. 2010;146(6):625-32.

7. Almeida S, Maillard C, Itin P, Hohl D, Huber M. Five new CYLD mutations in skin appendage tumors and evidence that aspartic acid 681 in CYLD is essential for deubiquitinase activity. J Invest Dermatol. 2007;128(3):587-93.

8. Gayathri SS, Alavandar E, Kumar SA. An analysis of skin appendageal tumors in South India. J Evol Med Dent Sci. 2012;1(6):907-12.

9. Saha A, Das NK, Gharami RC, Chowdhury SN, Datta PK. A clinico-histopathological study of appendageal skin tumors, affecting head and neck region in patients attending the dermatology opd of a tertiary care centre in eastern India. Indian J Dermatol. 2011;56(1):33-6.

10. Marla NJ, Naik R, Kumar P, Fernandes H, CS J, Pailoor K. Clinico-pathological study of adnexal tumors of skin. Adv Lab Med Int. 2014;4(4):122-7.

11. Sharma A, Paricharak DG, Nigam JS, Rewri S, Soni PB, Omhare A, et al. Histopathological sudy of skin adnexal tumours 2014;institutional study in South India 2014. Journal of Skin Cancer [Online Journal] 2014 [cited 2014 Desember 29]. Available from: http://www.hindawi.com/ journals/jsc/2014/543756/.

12. Yaqoob N, Gill M, Soomro I, Ahmad Z, Muzaffar S. Spectrum of cutaneous appendage tumors at Aga Khan University Hospital. J Pak Med Assoc. 2003;53:427.

13. Nair P. A clinicopathologic study of skin appendageal tumors. Indian J Dermatol Venereol Leprol. 2008;74:550.

14. Jindal U, Patel R. Study Of adnexal tumors Of the skin: A three year study of 25 cases. Internet J Pathol. 2012;13(3):1.

15. Alsaad K, Obaidat N, Ghazarian D. Skin adnexal neoplasms part 1: An approach to tumours of the pilosebaceous unit. J Clin Pathol. 2007;60(2):129-44. 